\title{
STUDI PENDAHULUAN MENGENAI DEGRADASI ZAT WARNA AZO (METIL ORANGE) DALAM PELARUT AIR MENGGUNAKAN MESIN BERKAS ELEKTRON $350 \mathrm{keV} / 10 \mathrm{~mA}$
}

\author{
MARIA ChristinA P. ${ }^{*}$., MU’NISATUN S. ${ }^{*}$., RANY SAPTAAJI ${ }^{* *}$, \\ DJOKO MARJANTO ${ }^{*}$ \\ *)Sekolah Tinggi Teknologi Nuklir - BATAN \\ Jl. Babarsari Kotak Pos 6101 YKBB Yogyakarta 55281 \\ Telepon 0274-484085, 489716, Faksimili 0274-489715 \\ **)Pustek Akselerator dan Proses Bahan - BATAN \\ Jl. Babarsari Kotak Pos 6101/YKBB Yogyakarta 55281 Telp. (0274) 488435
}

\begin{abstract}
Abstrak
STUDI PENDAHULUAN MENGENAI DEGRADASI ZAT WARNA AZO (METIL ORANGE) DALAM PELARUT AIR MENGGUNAKAN MESIN BERKAS ELEKTRON $350 \mathrm{keV} / 10 \mathrm{~mA}$. Telah dilakukan penelitian mengenai degradasi zat warna azo jenis metil orange menggunakan mesin berkas elektron $350 \mathrm{keV} / 10 \mathrm{~mA}$. Penelitian ini bertujuan untuk mengetahui pengaruh radiasi berkas elektron, yaitu pengaruh dosis radiasi, $\mathrm{pH}$, dan konsentrasi awal cuplikan. Selain itu dilakukan analisis kualitatif terhadap senyawa hasil degradasi. Proses iradiasi ini menggunakan dosis radiasi 5, 10, 20, 30 dan $40 \mathrm{kGy}$ dengan energi operasi $300 \mathrm{keV}$ dan kecepatan konveyor $2.7 \mathrm{~cm} /$ detik. Terhadap cuplikan ini diamati variasi $\mathrm{pH}$ dan variasi konsentrasi awal. $\mathrm{pH}$ metil orange diatur menjadi 2, 7, dan 12 dengan penambahan $\mathrm{H}_{2} \mathrm{SO}_{4} 6 \mathrm{~N}$ atau $\mathrm{NaOH} 6 \mathrm{~N}$. Konsentrasi awal divariasi menjadi 10, 50, dan $100 \mathrm{ppm}$. Efisiensi degradasi dihitung dengan mengukur pengurangan intensitas warna cuplikan setelah iradiasi menggunakan spektrofotometer UV-Vis. Untuk analisis kualitatif senyawa hasil degradasi digunakan alat High Performance Liquid Chromatography, HPLC Hasil penelitian ini menunjukkan, bahwa semakin besar dosis radiasi semakin besar pula efisiensi degradasi. Pada variasi $\mathrm{pH}$, efisiensi degradasi tertinggi diperoleh pada $\mathrm{pH} 2$ dengan efisiensi $37.74 \%$. Pada variasi konsentrasi awal, diperoleh efisiensi tertinggi pada konsentrasi awal $10 \mathrm{ppm}$ dengan efisiensi 21.54\%. Lama waktu iradiasi adalah kira-kira 2-5 detik.
\end{abstract}

Kata kunci: zat warna azo, degradasi, iradiasi berkas elektron

\begin{abstract}
PRELIMINARY STUDY OF AZO DYE (METHYL ORANGE) DEGRADATION IN WATER SOLUTION USING THE $350 \mathrm{keV} / 10 \mathrm{~mA}$ ELECTRON BEAM MACHINE. Research of methyl orange azo dye degradation had been done by using the electron beam machine $350 \mathrm{keV} / 10 \mathrm{~mA}$. The objective of the research was to measure the influence of electron beam radiation to the degradation of azo dye type methyl orange, the influence of radiation dose at different $\mathrm{pH}$ conditions, and initial concentration, and also to identify the degradation product. For irradiation process, it was used 5, 10, 20, 30 and $40 \mathrm{kGy}$ doses and operating energy of $300 \mathrm{keV}$ and conveyor speed at $2.7 \mathrm{~cm} / \mathrm{s}$. For the
\end{abstract}


methyl orange, it was used variation of $\mathrm{pH}$ and initial concentration. $\mathrm{pH}$ of methyl orange were arranged to 2, 7 and 12 with the addition $\mathrm{H}_{2} \mathrm{SO}_{4} 6 \mathrm{~N}$ and $\mathrm{NaOH} 6 \mathrm{~N}$, while variation of initial concentration were arranged to 10,50 , and $100 \mathrm{ppm}$. To determine the level of degradation efficiency, it was used spectrophotometer UV-VIS, while to investigate the compound of degradation product, it was used HPLC. Form result of the research indicated that for each variable: greater of radiation dose greater degradation efficiency. At various conditions of $\mathrm{pH}$, the highest of degradation efficiency obtained was at $\mathrm{pH} 2$ with the efficiency $37.74 \%$. At variation of initial concentration, a highest efficiency was obtained at initial concentration $10 \mathrm{ppm}$ with the efficiency $21.54 \%$. The irradiation time was approximately 2-5 seconds.

Keywords: azo dyes, degradation, electron beam irradiation

\section{PENDAHULUAN}

Dewasa ini pencemaran air menjadi masalah serius di dunia. Pencemaran senyawa non-biodegradable yang berasal dari limbah budidaya pertanian seperti herbisida, insektisida, fungisida, dan rodentisida, memberi sifat racun terhadap alam. Sama halnya dengan limbah industri berupa senyawa fenol, surfaktan, zat warna tekstil, poliklhorobifenil (PCB), pestisida, trikhloroetilen (TCE), dan senyawa aromatis lain, dapat menjadi sumber pencemar serius.

Beberapa cara pengolahan limbah konvensional telah banyak dilakukan, misalnya dengan cara khlorinasi, pengendapan dan penyerapan oleh karbon aktif, kemudian lumpur (sludge) yang terbentuk dibakar atau diproses secara mikrobiologi. Tetapi pembakaran sludge memicu terbentuknya senyawa khlorooksida, penggunaan karbon aktif hanya menyerap pencemar organik nonpolar dengan berat molekul rendah, sedangkan senyawa non polar dengan berat molekul tinggi tidak tereliminasi. Proses mikrobiologi hanya menguraikan senyawa biodegradable, sedangkan senyawa non-biodegradable tetap berada dalam sludge yang akan kembali ke lingkungan.

Salah satu pencemar organik yang bersifat non biodegradable adalah zat warna tekstil. Zat warna tekstil umumnya dibuat dari senyawa azo dan turunannya yang merupakan gugus benzena. Diketahui bahwa gugus benzena sangat sulit didegradasi, kalaupun dimungkinkan dibutuhkan waktu yang lama. Senyawa azo bila terlalu lama berada di lingkungan, akan menjadi sumber penyakit karena sifatnya karsinogen dan mutagenik. Karena itu perlu dicari alternatif efektif untuk menguraikan limbah tersebut.

Zat warna azo adalah senyawa yang paling banyak terdapat dalam limbah tekstil, yaitu sekitar $60 \%-70 \%{ }^{[1]}$. Senyawa azo memiliki struktur umum $\mathrm{R}-\mathrm{N}=\mathrm{N}-\mathrm{R}$ ', dengan $\mathrm{R}$ dan $\mathrm{R}^{\prime}$ adalah rantai organik yang sama atau berbeda. Senyawa ini memiliki gugus $-\mathrm{N}=\mathrm{N}-$ yang dinamakan struktur azo.

Nama azo berasal dari kata azote, merupakan penamaan untuk nitrogen bermula dari bahasa Yunani $a$ (bukan) + zoe (hidup). Untuk membuat zat warna 
azo ini dibutuhkan zat antara yang direaksikan dengan ion diazonium (seperti pada Gambar 1).
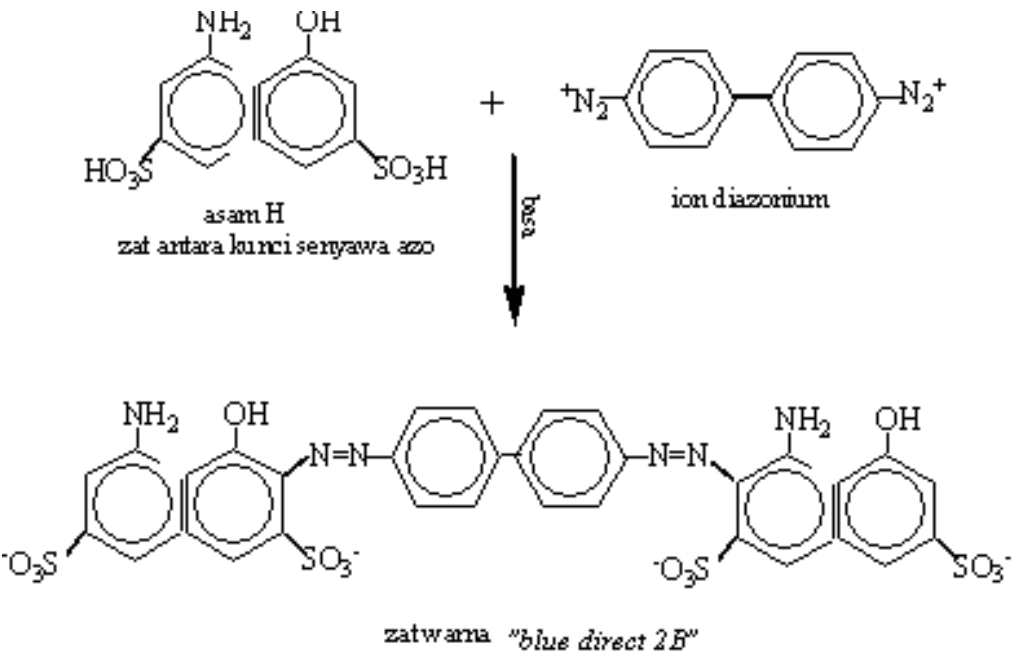

Gambar 1. Contoh Pembuatan Salah Satu Zat Warna Azo

Senyawa azo dapat berupa senyawa aromatik atau alifatik. Senyawa azo aromatik bersifat stabil dan mempunyai warna menyala. Senyawa azo alifatik seperti dimetildiazin (Gambar 2) lebih tidak stabil. Dengan kenaikan suhu atau iradiasi, ikatan nitrogen dan karbon akan pecah secara simultan melepaskan gas nitrogen dan radikal. Dengan demikian, beberapa senyawa azo alifatik digunakan sebagai inisiator radikal.<smiles>CN=NC</smiles>

Gambar 2. Dimetildiazin (Azometan)

Senyawa azo digunakan sebagai bahan celup, yang dinamakan azo dyes. Hanya sedikit zat warna azo yang dapat dioksidasi secara aerobik. Beberapa zat warna azo dapat diurai secara anaerobik setelah diolah dengan kondisi aerobik.

Cara efisien untuk menghasilkan pengoksidan dan reduktan dalam limbah cair adalah dengan iradiasi berkas elektron. Mesin Berkas Elektron (MBE) berdasarkan energinya dapat dibagi menjadi 3 macam ${ }^{[2]}$, yaitu :

1. MBE energi rendah menghasilkan elektron antara $100 \mathrm{keV}$ sampai $500 \mathrm{keV}$.

2. MBE energi sedang (medium) menghasilkan elektron antara $500 \mathrm{keV}$ sampai $5 \mathrm{MeV}$.

3. MBE energi tinggi menghasilkan elektron antara $5 \mathrm{MeV}$ sampai $10 \mathrm{MeV}$.

Komponen utama MBE terdiri dari : sumber elektron, sumber tegangan tinggi, tabung akselerator (pemercepat), sistem optik (pengarah, pemfokus dan 
pemayar), sistem hampa, sistem instrumentasi kendali, serta sistem conveyor. Berkas elektron dihasilkan oleh sumber elektron secara emisi termionik pada filamen yang dipanaskan. Setelah keluar dari sumber, dengan cara memasang tegangan listrik pada elektroda-elektroda tabung pemercepat, berkas elektron dilewatkan untuk dinaikkan energinya. Agar berkas elektron mengenai seluruh bahan yang diirradiasi, maka setelah keluar dari tabung pemercepat, berkas elektron disapu menggunakan sistem pemayar (scanning system). Material yang diiradiasi dilewatkan di bawah jendela MBE menggunakan sistem ban berjalan atau conveyor.

Interaksi antara radiasi pengion berupa berkas elektron dengan air akan menghasilkan spesi tereksitasi secara elektronik dan molekul terionisasi. Selanjutnya akan terbentuk spesi-spesi reaktif $\left(\mathrm{e}_{\mathrm{aq}}{ }^{-}, \mathrm{OH}^{*}, \mathrm{H}^{*}\right.$ dan $\mathrm{HO}_{2}{ }^{*}$ atau $\left.\mathrm{O}_{2}{ }^{*}\right)$ dan produk molekular $\left(\mathrm{H}_{2}\right.$ dan $\left.\mathrm{H}_{2} \mathrm{O}_{2}\right)$. Spesi-spesi tersebut merupakan produk primer radiolisis air yang keluar dari spur dan bereaksi dengan zat terlarut serta menguraikannya. ${ }^{[3]}$ Produk primer itu cenderung bereaksi dengan gugus fungsi molekul organik daripada molekul tersebut secara keseluruhan. ${ }^{[4] .}$

Radiasi pengion dapat digunakan untuk mengolah senyawa-senyawa organik berbahaya secara efektif, seperti alkil-halogen-hidrokarbon, aromatik hidrokarbon dan khlorobenzen dengan reaksi redoks. Bila senyawa itu diiradiasi pada kondisi berbasis air (aqueous), yang terjadi adalah proses degradasi (chain scissioning). Efek keseluruhan terhadap peristiwa degradasi adalah terjadi pengurangan berat molekul, yang dalam beberapa kasus produk akhir reaksi adalah molekul cairan dengan berat molekul rendah. ${ }^{[5]}$ Biasanya hasil akhir reaksi redoks ini adalah asam karboksilat, karbondioksida, air, dan garam anorganik ${ }^{[6]}$. Efisiensi pengolahan dari kontaminasi bahan kimia organik tergantung pada dosis radiasi, konsentrasi awal kontaminan, $\mathrm{pH}$ dan kekeruhan. ${ }^{[7,2]}$

Tujuan penelitian ini adalah mempelajari sejauh mana MBE hasil karya PTAPB (yang mempunyai energi yang relatif rendah) dapat didayagunakan untuk mendegradasi dan penghilangan warna (decolorization) limbah zat warna. Cara pencapaian tujuan itu adalah dengan mempelajari pengaruh radiasi berkas elektron, pengaruh dosis radiasi pada kondisi $\mathrm{pH}$ dan konsentrasi awal cuplikan, serta menganalisis hasil degradasi.

Pada penelitian awal ini, dipilih zat warna azo yang mudah ditemui di labaratorium yaitu metil orange. Zat warna ini digunakan sebagai cuplikan zat warna tekstil. Dengan diperolehnya informasi dari hasil penelitian ini nanti, diharapkan akan dapat dilanjutkan penelitian yang berkesinambungan terkait dengan pengolahan limbah menggunakan fasilitas MBE. 


\section{METODE PENELITIAN}

\section{Bahan}

Bahan yang digunakan dalam penelitian ini antara lain : serbuk metil orange, film CTA (Cellulose Triacetate), $\mathrm{H}_{2} \mathrm{SO}_{4} 6 \mathrm{~N}, \mathrm{NaOH} 6 \mathrm{~N}$, aquades, dan alkohol.

\section{Alat}

Peralatan dan fasilitas yang digunakan dalam penelitian ini: Mesin Berkas Elektron $350 \mathrm{keV} / 10 \mathrm{~mA}$ dengan ukuran berksa $1200 \mathrm{~mm} \times 60 \mathrm{~mm}$, kecepatan konveyor 2,7 cm/detik. spektrofotometer dengan perangkat lunak Genesys CTA reader, spektrofotometer UV-Vis, instrumen kromatografi cair kinerja tinggi (High Performance Liquid Chromatography, HPLC), berbagai piranti gelas, wadah cuplikan dari kaca berbentuk baki, $\mathrm{pH}$ meter dan vial-vial plastik.

\section{Cara Kerja}

1. Preparasi Cuplikan

a. Variasi konsentrasi

Dibuat larutan induk zat warna azo 1000 ppm dengan melarutkan serbuk 0,25 gram metil orange dalam $10 \mathrm{ml}$ alkohol kemudian ditandabataskan dengan aquades sampai $250 \mathrm{~mL}$. Dari larutan induk, dibuat variasi konsentrasi 100, 50, dan 10 ppm. pH larutan masing-masing cuplikan itu adalah netral.

b. Variasi $\mathrm{pH}$

Dibuat $500 \mathrm{~mL}$ cuplikan dengan konsentrasi $50 \mathrm{ppm}$. Kemudian dibuat variasi $\mathrm{pH} 3$, 7, dan 11. Untuk membuat larutan asam ditambahkan larutan $\mathrm{H}_{2} \mathrm{SO}_{4}$, sedangkan untuk larutan basa ditambahkan larutan $\mathrm{NaOH}$.

2. Iradiasi cuplikan dan penentuan dosis radiasi

Dosimeter film CTA dipotong sepanjang $\pm 7 \mathrm{~cm}$ dan ditempelkan pada selembar amplop. Larutan zat warna metil orange disiapkan dalam wadah kaca, dan diberi label. Cuplikan diiradiasi dengan dosimeter CTA pada variasi dosis 5, 10, 20, 30, $40 \mathrm{kGy}$ dan tegangan $300 \mathrm{keV}$, arus disesuaikan dosis yang diinginkan dan kecepatan konveyor 2,7 cm/detik. Waktu iradiasi cuplikan kira-kira 2-5 detik. Iradiasi Film CTA yang telah diiradiasi didiamkan dalam suhu kamar selama 2 jam, kemudian diukur rapat optiknya menggunakan spektrofotometer. Rapat optik CTA itu sebanding dengan dosis serap.

3. Analisis cuplikan hasil degradasi

Analisis kuantitatif dilakukan untuk mengetahui perubahan akibat iradiasi berdasarkan perubahan intensitas atau pengurangan intensitas warna, menggunakan spektrofotometer UV-Vis. Pengukuran intensitas warna dilakukan pada panjang gelombang tertentu pada kondisi terjadi penyerapan maksimum. Kurva kalibrasi dibuat menggunakan larutan standar metil orange dengan konsentrasi 2, 3, 4, 5, 6, dan 7 ppm. 
Analisis kualitatif asam oksalat (sebagai indikasi terjadinya degradasi) dalam cuplikan yang telah diiradiasi dibandingkan dengan yang tidak diiradiasi, dilakukan menggunakan HPLC dan secara pengendapan menggunakan larutan $\mathrm{CaCl}_{2}$.

\section{HASIL DAN PEMBAHASAN}

\section{Metil Orange Sebagai Zat Warna Azo}

Senyawa azo seperti metil orange (Gambar 3), dapat digunakan sebagai indikator asam, karena dapat berfungsi sebagai asam lemah yang berbeda warna antara asam dan garamnya. ${ }^{[8]}$

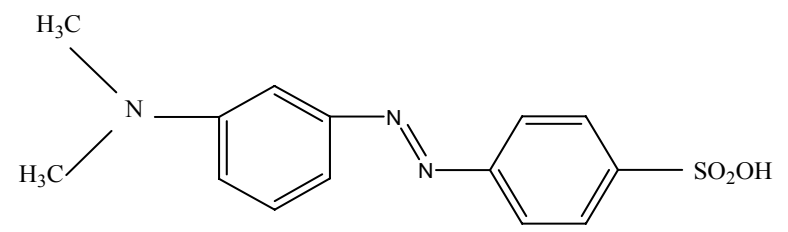

Gambar 3. Metil Orange Sebagai Contoh Senyawa Azo Aromatik

\section{Mekanisme Degradasi Zat Warna Azo oleh Berkas Elektron}

Pada proses iradiasi awal, berkas elektron cepat yang dihasilkan MBE dapat mengeksitasi dan mengionisasi sistem di sekitarnya. Proses iradiasi terjadi hanya dalam beberapa detik (kira-kira paling lama 5 detik). Karena cuplikan dilarutkan dalam sistem air, maka dalam sistem itu elektron cepat akan berinteraksi dengan air membentuk track-track berupa spurs, short track, dan blobs. Spesi-spesi itu tidak terdistribusi secara merata tergantung pada linear energy transfer (LET) dari elektron tersebut. Dari spurs tersebut timbul spesi-spesi reaktif dengan mekanisme reaksi seperti pada Gambar 4. Laju kecepatan terbentuknya radikalradikal di atas dipengaruhi oleh $G$ value masing-masing radikal.

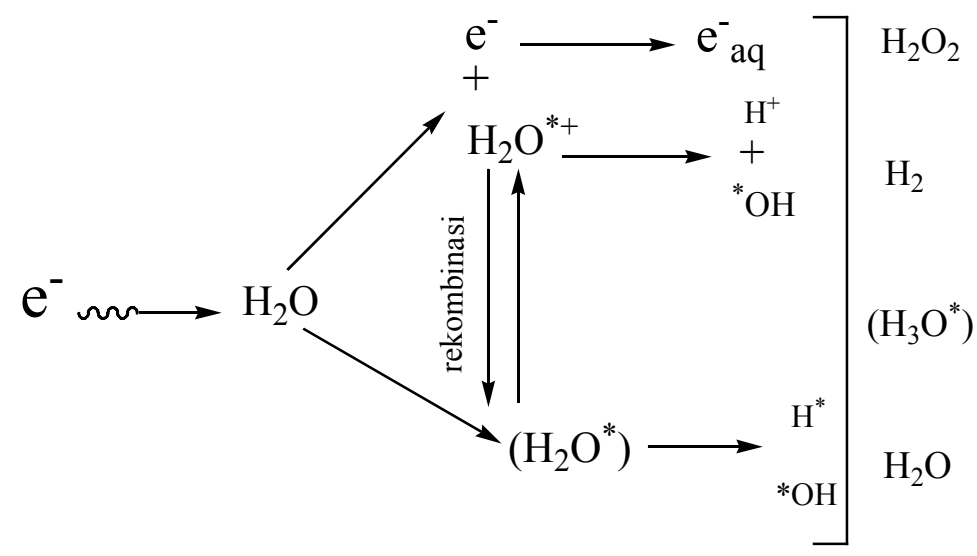

Gambar 4. Skema Pembentukan Berbagai Radikal dalam Sistem Larutan Air 
Dalam sistem itu sangat mungkin terjadi banyak peristiwa rekombinasi seperti: radikal $\mathrm{H}^{\bullet}$ dengan ${ }^{\bullet} \mathrm{OH}$ membentuk molekul air, elektron tersolvasi $\left(\mathrm{e}_{\mathrm{aq}}^{-}\right)$dengan • $\mathrm{OH}$ membentuk ion $\mathrm{OH}^{-}$, elektron tersolvasi $\left(\mathrm{e}^{-}\right.$aq $)$dalam suasana asam $\left(\mathrm{H}_{3} \mathrm{O}^{+}\right)$ membentuk radikal $\left(\mathrm{H}_{3} \mathrm{O}^{\circ *}\right)$, dan seterusnya. Selanjutnya spesi-spesi reaktif itu akan mendegradasi senyawa azo.

Berdasarkan studi literatur (state of the art) mengenai fenomena kimia radiasi dan induksi radiasi pada polutan yang terlarut dalam air ${ }^{[9]}$, mekanisme degradasi terhadap senyawa azo meteil orange dapat diperkirakan terjadi seperti pada Gambar 5 dan Gambar 6.

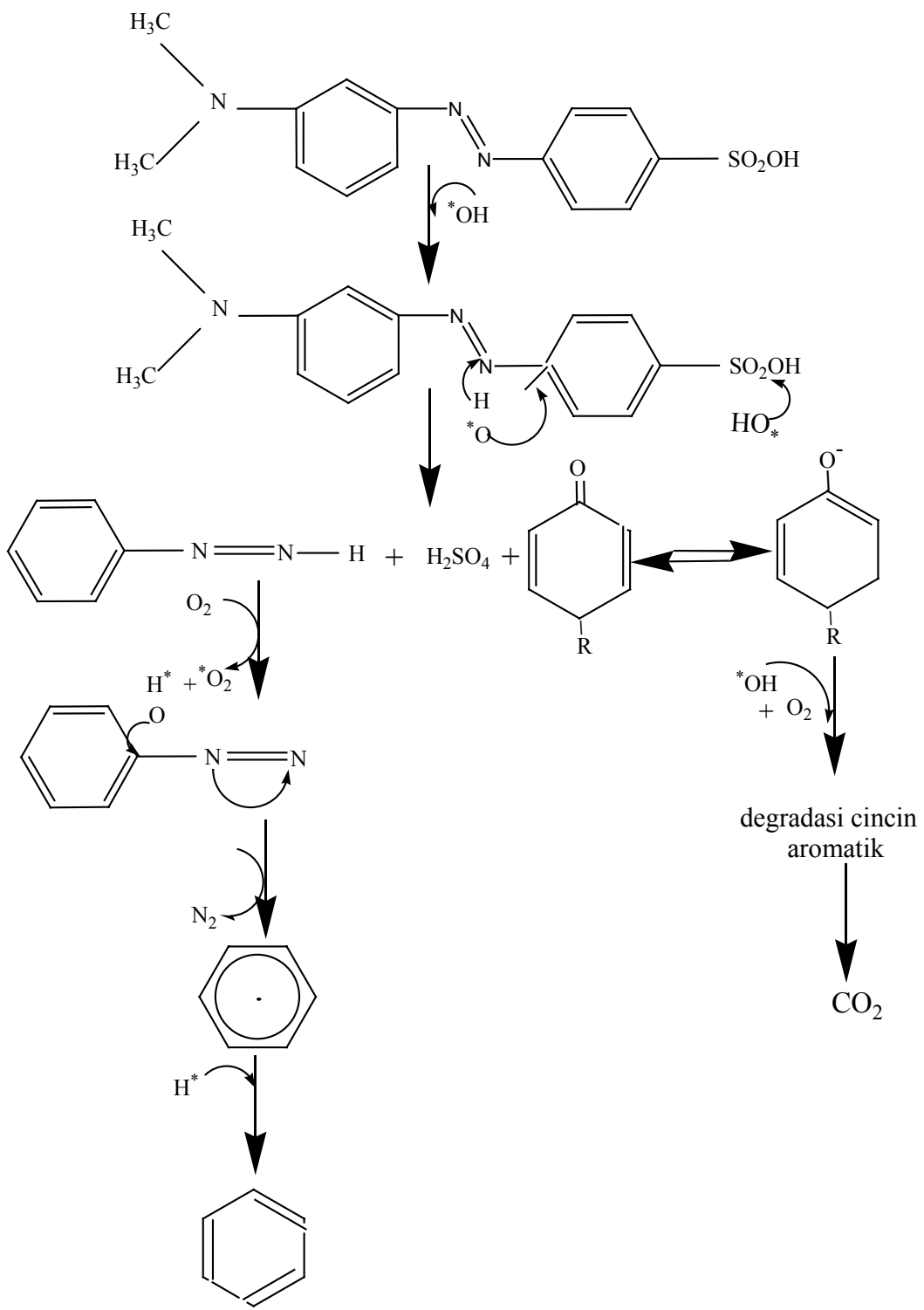

Gambar 5. Tahapan Reaksi Degradasi Senyawa Azo Metil Orange 
Gambar 5 menunjukkan Radikal hidroksil adalah radikal utama yang melakukan inisiasi degradasi pada gugus utama senyawa azo, dengan memhangsilkan radikal fenil dan fenoksi. Pada tahap berikutnya dengan adanya oksigen terlarut, akan terjadi abstraksi ion hidrogen dan radikalnya, pada radikal fenil.Pada tahap lebih lanjut akan keluar gas nitrogen yang diikuti dengan proses reduksi pada radikal cincin bensen menjadi senyawa aromatik sederhana. Di sisi lain, gugus radikal fenoksi akan teroksidasi oleh radikal hidroksil menjadi gugus benzena.

Gambar 6, adalah tahap reaksi degradasi pada gugus benzena.

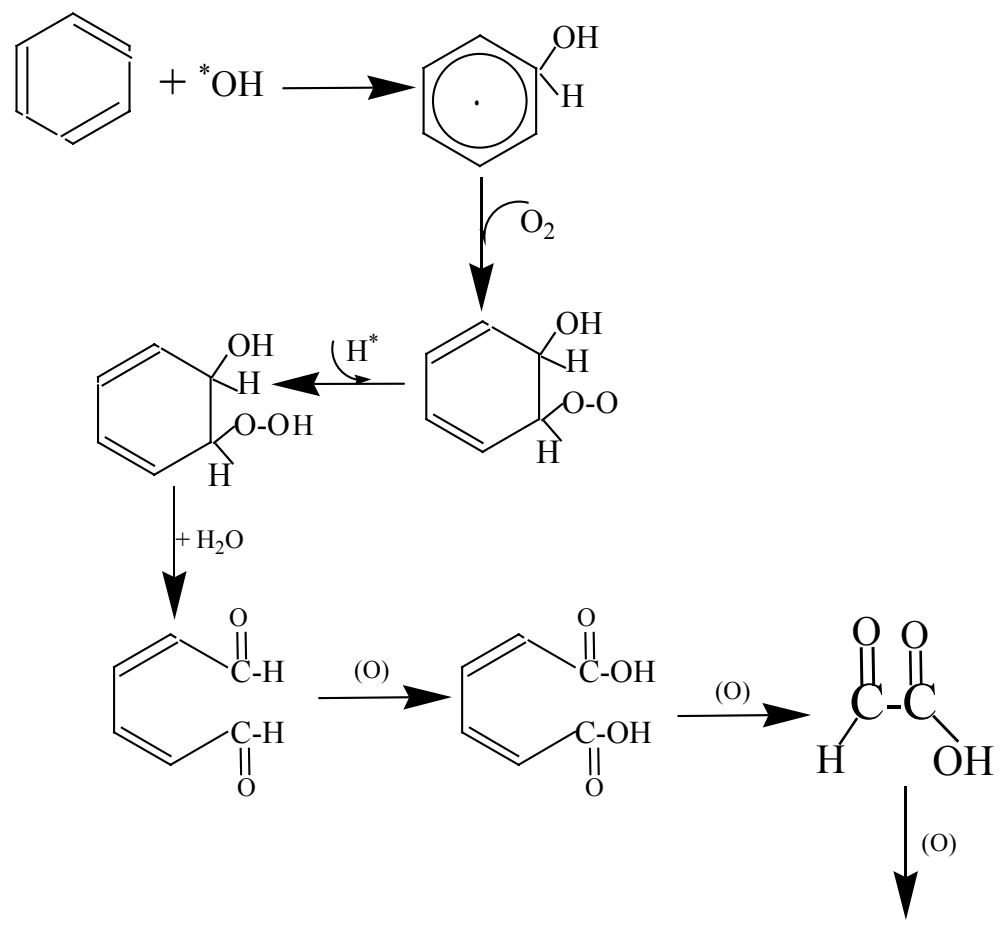<smiles>O=C(O)C(=O)O</smiles>

Gambar 6. Tahapan Reaksi degradasi Senyawa Azo Metil Orange

Pada Gambar 6, cincin aromatik benzena akan terdegradasi menjadi radikal hidroksisikloheksadienil. Radikal ini akan berekasi dengan oksigen terlarut menghasilkan hidroksi hidroperoksida yang tidak stabil. Reaksi berikutnya adalah terjadinya penghilangan satu molekul air dan pembentukan cincin aromatis dari hidroksi hidroperoksida menjadi mukondialdehid. Mukodialdehid kemudian teroksidasi mejadi asam mukanot Pada proses oksidasi selanjutnya akan terbentuk glioksial yang kemudian teroksidasi menjadi asam karboksilat. 
Proses iradiasi dengan MBE yang berlangsung dalam orde waktu beberapa detik saja, telah cukup untuk menghasikan spesi-spesi reaktif yang kemudian memicu reaksi kimia dalam solute metal orange. Pada studi awal ini baru dipelajari beberapa parameter yang fundamental, dan belum dilakukan peninjauan kinetika reaksi.

\section{Pengaruh dosis radiasi terhadap pH larutan yang berbeda}

Bila pengurangan konsentrasi zat warna setara dengan pengurangan intesitas warna cuplikan maka efisinsi degradasi dapat dijadikan variabel terikat dalam penelitian ini. Dalam hal ini efisiensi degradasi adalah persentase pengurangan intensitas warna metil orange setelah diiradiasi.

Kurva kalibrasi hasil pengukuran larutan standar metal orange dengan UVVis Spektrofotometer pada panjang gelombang $504 \mathrm{~nm}$ ditunjukkan seperti pada Gambar 7.

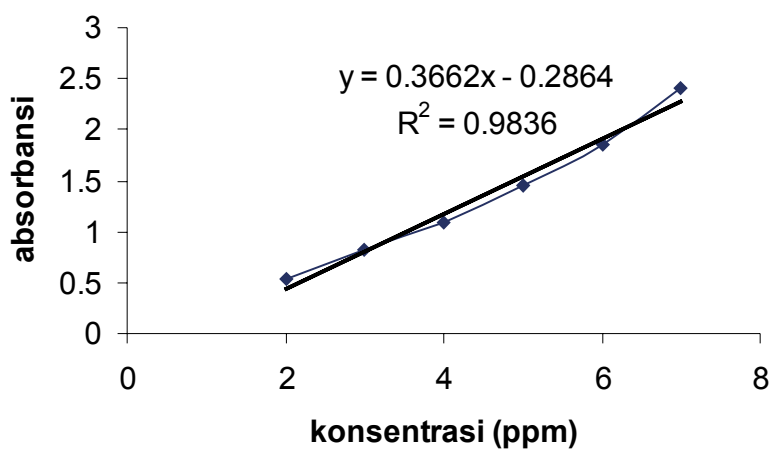

Gambar 7. Kurva Kalibrasi Larutan Standar Metil Orange

Hasil perhitungan efisiensi degradasi metil orange pada kondisi $\mathrm{pH}$ yang berbeda diberikan pada Gambar 8.

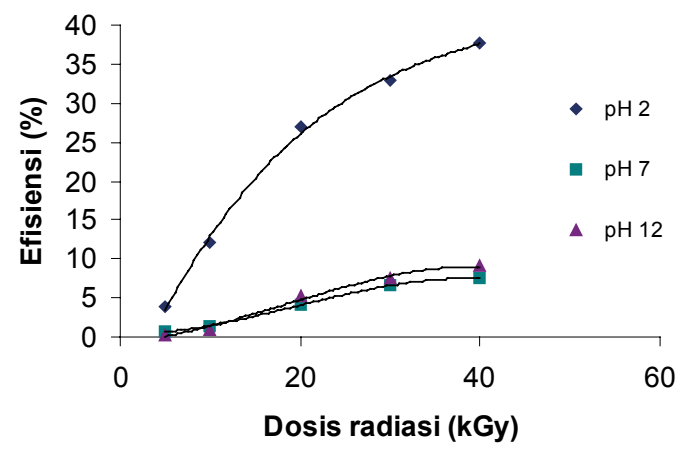

Gambar 8. Grafik Hubungan Antara Dosis Radiasi vs Efisiensi untuk Variasi pH pada Konsentrasi Larutan 50 ppm. 
Untuk mengetahui pengaruh dosis radiasi pada kondisi $\mathrm{pH}$ yang berbeda, dilakukan pengamatan terhadap larutan pada kondisi asam, netral dan basa yaitu dengan mengatur larutan metil orange pada kondisi $\mathrm{pH} \mathrm{2,} 7$ dan 12. Pada penentuan pengaruh $\mathrm{pH}$ ini, konsentrasi awal larutan dibuat sama, baik pada $\mathrm{pH}$ 2, 7 dan 12 dengan konsentrasi sebesar 50 ppm. Hasil perhitungan efisiensi degradasi terhadap perubahan dosis radiasi, dibuat ke dalam grafik menggunakan persamaan garis polinomial orde 3 diperoleh persamaan : Untuk $\mathrm{pH} 2$ :y $=0,0004$ $\mathrm{x}^{3}-0,0526 \mathrm{x}^{2}+2,6024 \mathrm{x}-8,2145$, dengan $\mathrm{R}^{2}=0,9977$. Untuk $\mathrm{pH} 7: \mathrm{y}=0,0003$ $\mathrm{x}^{3}+0,0155 \mathrm{x}^{2}-0,0194 \mathrm{x}+0,372$, dengan $\mathrm{R}^{2}=1$. Untuk $\mathrm{pH} 12: \mathrm{y}=0,0003 \mathrm{x}^{3}+$ $0,0143 \mathrm{x}^{2}+0,0893 \mathrm{x}-0,6716$, dengan $\mathrm{R}^{2}=0,991$

Dari Gambar 7 terlihat bahwa semakin bertambah dosis, maka efisiensi degradasi metil orange juga semakin besar. Pada kondisi $\mathrm{pH} 2$ terjadi peningkatan efisiensi degradasi metil orange yang lebih signifikan daripada $\mathrm{pH} 7$ dan 12, dengan efisiensi degradasi tertinggi 37,74 \% pada dosis $40 \mathrm{kGy}$, sedangkan pada $\mathrm{pH} 7$ dan 12 peningkatan efisiensi hampir sama, yaitu pada dosis $40 \mathrm{kGy}$ efisiensi tertinggi masing-masing 7,46\% dan 9,08\%. Nilai $\mathrm{pH}$ larutan menentukan besarnya macam spesies primer hasil radiolisis air $\left(\mathrm{e}_{\mathrm{aq}}{ }^{-}, \cdot \mathrm{H}, \cdot \mathrm{OH}\right)$ sehingga akan mempengaruhi pengurangan konsentrasi zat warna.

Pada $\mathrm{pH} 2$, persen efisiensi degradasi zat warna metil orange lebih tinggi dari pada $\mathrm{pH} 7$ dan 12. Hal ini dapat ditinjau dari keberadaan elektron terhidrat dan radikal hidrogen dalam larutan $\mathrm{pH} 2$ elektron terhidrat lebih banyak daripada pH 7. Elektron terhidrat dan radikal hidrogen merupakan pereduksi kuat, dan keduanya dapat melakukan reaksi adisi pada ikatan rangkap $\mathrm{N}=\mathrm{N}$. Pada $\mathrm{pH}$ yang relatif tinggi atau basa, radikal hidroksil akan dikonversi menjadi radikal $\mathrm{O} \cdot$ Radikal $\mathrm{O}^{-}$mempunyai kecenderungan yang lebih rendah daripada radikal hidroksil terhadap reaksi adisi pada ikatan rangkap $\mathrm{N}=\mathrm{N}$.

\section{Pengaruh dosis radiasi terhadap konsentrasi awal larutan}

Hasil perhitungan efisiensi degradasi terhadap metil orange pada konsentrasi awal yang berbeda diperlihatkan pada Gambar 9. Pada pengamatan pengaruh dosis radiasi terhadap konsentrasi awal yang berbeda, konsentrasi awal larutan metil orange dibuat 10, 50 dan 100 ppm. Hasil perhitungan efisiensi degradasi terhadap perubahan dosis radiasi, dibuat ke dalam grafik menggunakan persamaan garis polinomial orde 3 , diperoleh persamaan : Untuk konsentrasi awal 10 ppm ; $y=0,001 \mathrm{x}^{3}-0,0663 \mathrm{x}^{2}+0,6373 \mathrm{x}-2,2416$, dengan $\mathrm{R}^{2}=0,9999$. Untuk konsentrasi awal $50 \mathrm{ppm} ; \mathrm{y}=0,0005 \mathrm{x}^{3}-0,0373 \mathrm{x}^{2}+0,9766 \mathrm{x}-2,5871$, dengan $\mathrm{R}^{2}=0,9797$. Untuk konsentrasi awal $100 \mathrm{ppm} ; \mathrm{y}=0,0012 \mathrm{x}^{3}-0,0761 \mathrm{x}^{2}$ $+1,7 \mathrm{x}-6,5565$, dengan $\mathrm{R}^{2}=0,9957$. Dari Gambar 9 terlihat bahwa semakin bertambah dosis, maka efisiensi degradasi metil orange juga semakin besar. Pada konsentrasi awal 10 ppm terjadi peningkatan efisiensi degradasi yang paling signifikan daripada konsentrasi awal 50 dan 100 ppm, dengan efisiensi tertinggi 
$21.56 \%$ pada dosis $40 \mathrm{kGy}$. Pada konsentrasi 50 dan 100 ppm penurunan pada dosis $40 \mathrm{kGy}$ efisiensi tertinggi masing-masing 7,11\% dan $14.84 \%$.

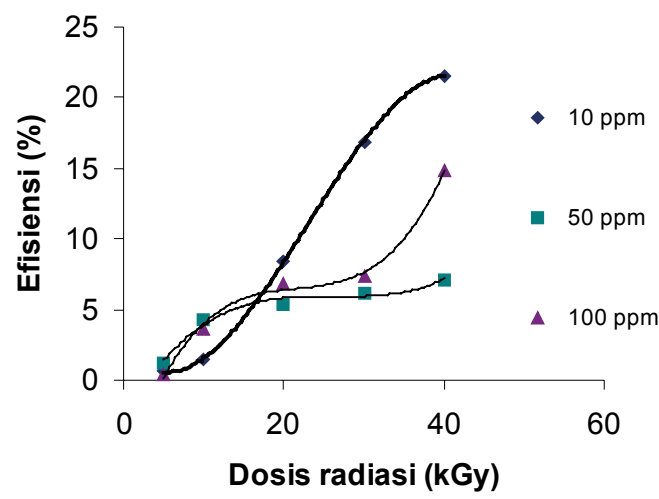

Gambar 9. Grafik Hubungan Antara Dosis Radiasi vs Efisiensi untuk Variasi Konsentrasi pada Kondisi pH Larutan yang Dibuat Netral

Penguraian tertinggi pada konsentrasi awal 10 ppm ini terjadi karena zat terlarut lebih sedikit dibandingkan pada konsentrasi 50 dan 100 ppm. Pada konsentrasi awal yang lebih besar, spesi reaktif hasil radiolisis air yang terjadi jauh lebih sedikit jika dibandingkan dengan zat terlarut, sehingga zat terlarut yang bereaksi dengan spesi reaktif juga hanya sedikit.

\section{Perubahan pH saat Iradiasi}

$\mathrm{pH}$ larutan metil orange setelah diradiasi mengalami perubahan. Pada Gambar 10 dan Gambar 11 dapat dilihat perubahan $\mathrm{pH}$ larutan zat warna metil orange setelah diradiasi.

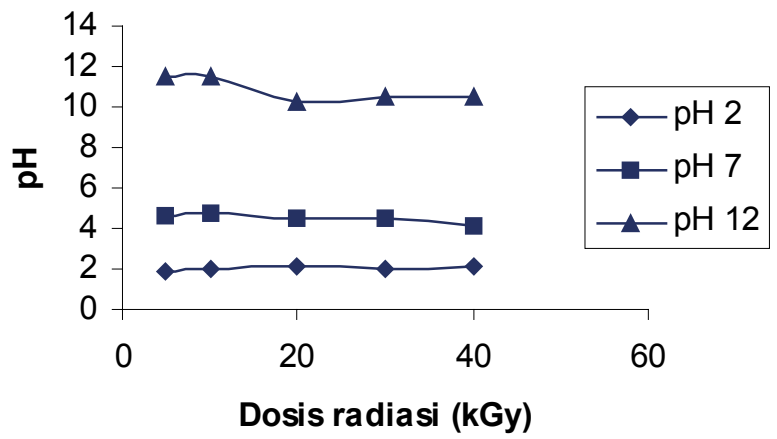

Gambar 10. Perubahan $\mathrm{pH}$ Larutan pada Iradiasi Metil Orange pada Berbagai Variasi pH Awal Pada larutan $\mathrm{pH}$ awal 2 perubahan $\mathrm{pH}$ relatif tetap, untuk $\mathrm{pH}$ awal 7 dan 12 masing-masing mengalami penurunan $\mathrm{pH}$ larutan. Penurunan $\mathrm{pH}$ larutan 
disebabkan oleh penguraian zat warna menjadi senyawa sederhana dengan berat molekul yang lebih rendah, seperti terbentuknya asam-asam organik.

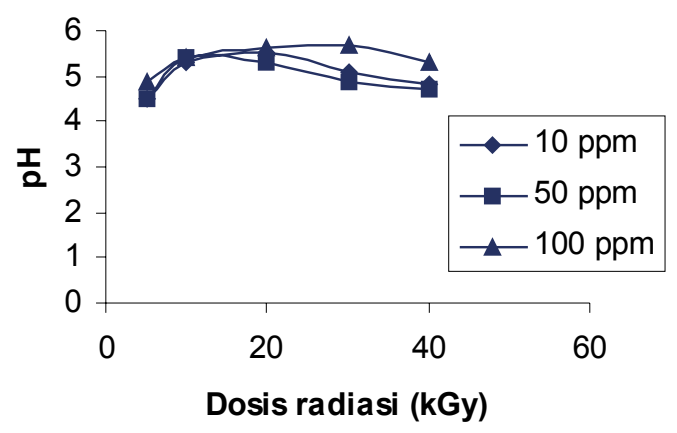

Gambar 11. Perubahan pH Larutan pada Iradiasi Metil Orange pada Berbagai Variasi Konsentrasi Awal

\section{Hasil analisis larutan metil orange menggunakan HPLC}

Untuk mengetahui salah satu senyawa hasil degradasi yaitu asam oksalat, larutan metil orange yang diradiasi maupun yang tidak diradiasi dianalisis menggunakan HPLC (High Performance Liquid Chromatography).

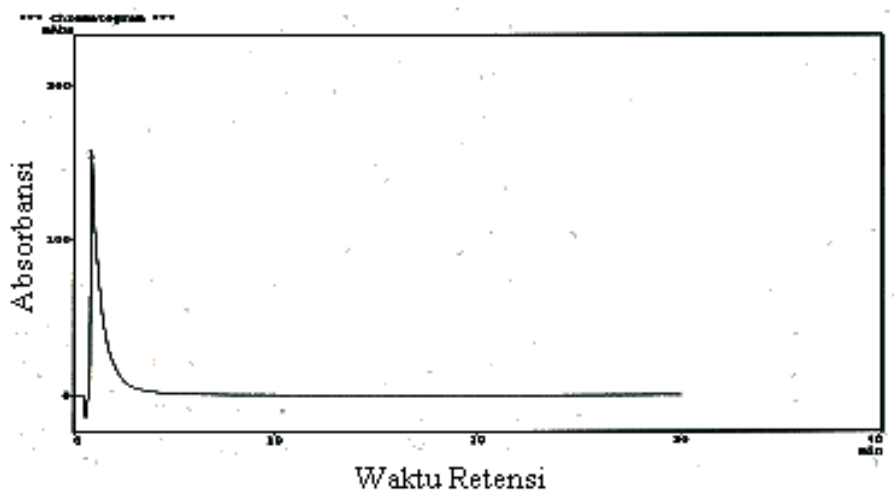

Gambar 12. Kromatogram Larutan Standar Asam Oksalat.

Pada Gambar 12, kromatogram standar asam oksalat diperoleh puncak absorbansi yaitu puncak 2, pada waktu retensi 0.890 menit. Pada Gambar 13 kromatogram larutan metil orange yang tidak diradiasi, puncak 2 menunjukkan puncak spektrum asam oksalat dengan waktu retensi 1.015 menit diperoleh absorbansi \pm 6 . Pada Gambar 14 kromatogram larutan metil orange yang tidak diradiasi, puncak 2 yang merupakan puncak spektrum asam oksalat pada waktu retensi 1.039 diperoleh absorbansi \pm 25 . 


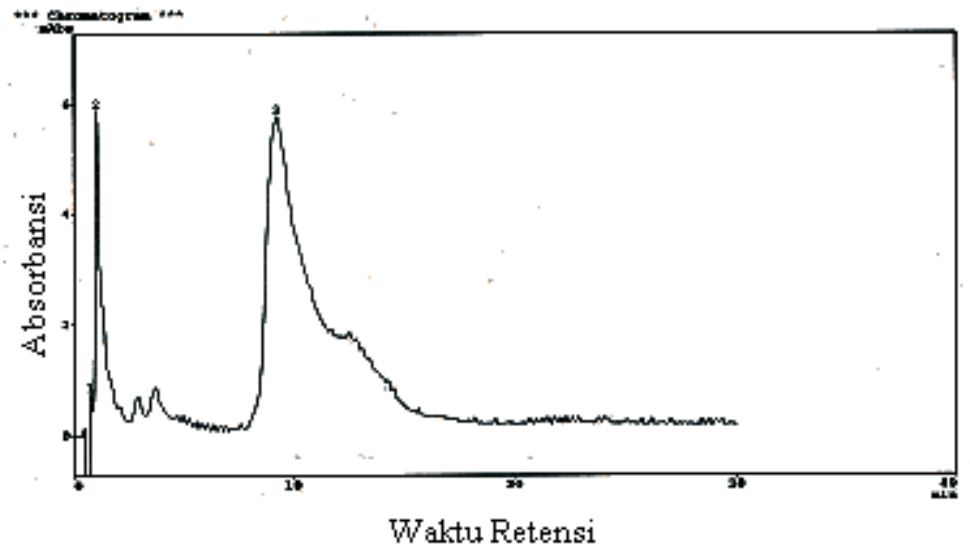

Gambar 13. Kromatogram Larutan Metil Orange 50 ppm Yang Tidak Diradiasi

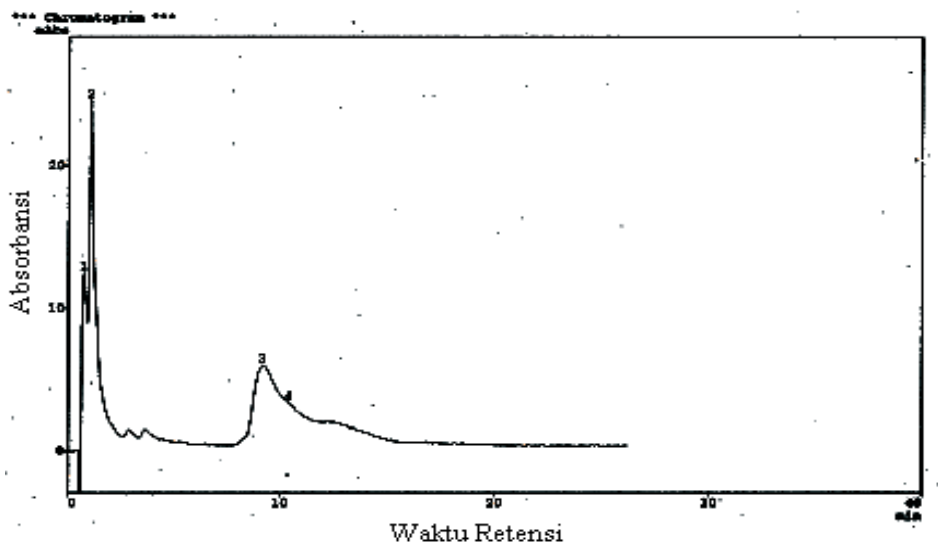

Gambar 14. Kromatogram Larutan Metil Orange 50 ppm Setelah Radiasi

Dari kromatogram hasil analisis dengan HPLC tersebut, terlihat bahwa larutan metil orange yang tidak diradiasi maupun yang diradiasi terdapat asam oksalat. Namun, terjadi peningkatan asam oksalat yang signifikan dalam larutan metil orange yang diradiasi, sehingga dapat dipastikan bahwa radiasi berkas elektron dapat digunakan untuk degradasi zat warna dalam pelarut air. Adanya asam oksalat pada larutan metil orange yang tidak diradiasi ini diperkirakan karena larutan metil orange terdegradasi secara lambat oleh radiasi ultra violet selama penyimpanan.

\section{KESIMPULAN}

Dari hasil penelitian tentang degradasi zat warna azo jenis metil orange dalam pelarut air menggunakan mesin berkas elektron $350 \mathrm{keV} / 10 \mathrm{~mA}$ dapat disimpulkan bahwa : 
1. Radiasi pengion dari berkas elektron dapat digunakan untuk degradasi zat warna. Semakin tinggi dosis radiasi maka efisiensi degradasi semakin besar. Hal ini terjadi pada semua variabel. Pada setiap dosis $40 \mathrm{kGy}$ terjadi penguraian terbesar, baik pada variasi konsentrasi maupun variasi $\mathrm{pH}$.

2. Pada pengaruh dosis radiasi terhadap kondisi $\mathrm{pH}$ yang berbeda, efisiensi degradasi tertinggi diperoleh pada $\mathrm{pH}$ 2, yaitu $37.74 \%$ dan pada pengaruh dosis radiasi terhadap konsentrasi awal yang berbeda diperoleh efisiensi degradasi tertinggi pada konsentrasi awal 10 ppm, yaitu $21.56 \%$.

\section{DAFTAR PUSTAKA}

1. WAITE, TD., et al., 2006, "Toxic Organic Destruction by Electron Beam Irradiation : An Innovative Technology for Developing Countries", University of Miami, Coral Gables, Florida.

2. DJALOEIS, A., 1996, "Pengembangan Teknologi Akselerator dan Pemanfaatannya di Indonesia", Prosiding Pertemuan dan Presentasi Ilmiah, PPNY-BATAN, Yogyakarta.

3. FRANCIS, A., 2003, “Application of Radiation Technology for The Treatment of Toxic and Recalcitrant Pollutants in Water", Review and Research Proposal for Master's Thesis, Shanghai University: School of Environmental and Chemical Engineering, Shanghai, China.

4. WAHYUNI, S dan RAHMAWATI, 2005, 'Pemanfaatan Mesin Berkas Elektron untuk Mengolah Limbah Cair Industri’, Majalah Media Kita, Edisi Maret 2005

5. CHAPIRO, A., 1961, Radiation Chemistry of Polimeric System, John Wiley \& Sons, New York-London

6. MIYATA, T., 1995, "Radiation Chemistry of Water System, Department of Environment and Resources", Takasaki Radiation Chemistry Research Establishment, JAERI.

7. TROJANOWICZ, M. et. al., 2000, "Application of ionizing radiation for degradation of organic pollutants in waters and wastes".

8. http://en.wikipedia.org/wiki/azo_compound, diakses 12 Agustus 2006.

9. GETOFF, N., 1996, Radiation-induced degradation of water pollutants state of the art, Radiat. Phys. Chem, 47, 581-593 